\title{
Mean arterial pressure, pulse pressure in diabetic and non diabetic male African population: a comparative study
}

\begin{abstract}
Objective: Mean arterial pressure (MAP) and pulse pressure (PP) are important parameters that predict cardiovascular risk both in diabetics and non diabetic population in both genders. Data on this subject area in Nigeria, Africa and worldwide are few. The aim of this paper is to examine the pattern of MAP and PP in a diabetic male population compared to a general population of males in Africans. Is the pattern of MAP and PP the same in both diabetic and non diabetic? Does any significant disparity exist?
\end{abstract}

Methods: This is a preliminary prospective study. Randomly, the blood pressure of 20 men from the general Lagos population was taken at heart level using a mercurial sphygmomanometer during a free medical screening exercise in surlier. Similarly, the blood pressure of 20 consecutive known diabetic men was taken at heart level using a mercurial sphygmomanometer. The diabetic patients were recruited from the endocrinology clinic of the Lagos State University Teaching Hospital, Ikeja, and Lagos, Nigeria. Individual consent was obtained from both groups of participants. The PP of each individual was computed by subtracting the diastolic blood pressure from the systolic blood pressure. The MAP of each individual was computed by adding one third of the PP to the diastolic blood pressure. The limitation of this study includes the very small size of the study population and Africans are not well represented in the sample size.

Results or case presentation: The age range of the non diabetic was 31 to $70 y e a r s$ while the age range of the diabetics was 31 to 82 years. The mean(average) pulse pressure among the non diabetic was $46.5 \mathrm{mmHg}$ while the average pulse pressure among the diabetics was $67.7 \mathrm{mmHg}$. Among the non diabetic the mean of the MAP was $103.20 \mathrm{mmHg}$ while among the diabetics it was $96.97 \mathrm{mmHg}$. The highest MAP among the diabetic group was $133.33 \mathrm{mmHg}$ while the highest among the non diabetic was $150 \mathrm{mmHg}$.

Discussion: This paper shows that the average MAP is higher in the general African male population than among diabetic male Africans. This supports autopsy finding in literature that hemorrhagic cerebra vascular accident occurs slightly more commonly in non diabetic compared to diabetics while cerebral infarction occurs more in diabetic subjects compared to non diabetics. Similarly it was noticed in the study that African male diabetics tend to have higher pulse pressure than the general African population.

Conclusion: MAP is lower in male African diabetics compared to the general African male population. Conversely, PP is higher among male African diabetics compared to the general African male population.
Research Article

Volume 5 Issue 2 - 2018

\section{Ademolu B Adegbenga}

Medicine Department, Lagos State University Teaching Hospital, Nigeria

Correspondence: Adegbenga B Ademolu, Medicine Department, Lagos State University Teaching Hospital, Ikeja, Lagos, Nigeria, Tel +2348033575940, Email

ademoluab@yahoo.com

Received: February 01, 2018 | Published: March 05, 2018

Keywords: Mean Arterial Pressure, Pulse Pressure, Diabetics, Non Diabetics

\section{Introduction}

Mean arterial pressure and pulse pressure are important parameters that predicts cardiovascular risk both in diabetics and non diabetic population in both gender. Data on this subject area in Nigeria, Africa and worldwide are few. It was estimated that in the United States $30 \%$ of inpatient cost (around 22,254 million US dollars) was due to cardiovascular vascular disease (CVD) hospitalization among people with type 2 diabetes in 2012., ${ }^{1,2}$ An even greater diabetes-attributable hospitalization cost of $46.5 \%$ was found in a major hospital in
Cambridge shire, England. ${ }^{3}$ A paradoxical finding is that the wellknown relationship between CVD and systolic blood pressure in the general population was insignificant in a meta-analysis using data from people with diabetes. ${ }^{4}$ Greater use of antihypertensive medicine and a higher prevalence of heart failure than people without diabetes have been proposed as possible reasons for this paradox. ${ }^{5,6}$ Mean arterial pressure (MAP) reflects both peripheral resistance and cardiac output. Recently, in the ADVANCE study, ${ }^{7}$ a trial among type 2 diabetes patients, MAP correlated with major CVD events: with a $13 \%$ increase in risk per $13 \mathrm{mmHg}$ increase in MAP. If MAP is a marker for 
CVD risk among type 2 diabetes patients, it should be associated with greater CVD hospitalization. However, the association between MAP and hospitalization in type 2 diabetes has not been investigated, and a dose-response relationship between CVD hospitalization and MAP may exist. Moreover, blood pressure and CVD are influenced by long term glycemic control, ${ }^{8-12}$ usually assessed using $\mathrm{HbA} 1 \mathrm{c}$, which also has an association with hospitalization risk. ${ }^{13}$

The pulse pressure is the difference between the systolic and diastolic blood pressure. It is influenced by the stroke volume and vascular resistance. As people age the walls of their arteries become stiffer. This increases the pulse pressure. A high pulse pressure may be associated with reduced coronary perfusion. It may therefore be a predictor of future cardiovascular events, but this has not been confirmed by meta-analysis. ${ }^{14}$ Classically, a wide (high) pulse pressure is a sign of aortic valve regurgitation and a narrow (low) pulse pressure is a sign of aortic stenosis. In the absence of valvular disease, a high pulse pressure may be a sign of stiffness in the arterial walls, and is a risk factor for coronary artery disease and myocardial infarction. The aim of this paper is to examine the pattern of mean arterial pressure and pulse pressure in a diabetic male population compared to a general population of males in Africans. Is the pattern of mean arterial pressure, pulse pressure the same in both diabetic and non diabetic? Does any significant disparity exist?

\section{Methodology}

This is a preliminary comparative prospective study that looks into the mean arterial pressure and pulse pressure of a diabetic and non diabetic male population in Africa. Randomly, the blood pressure of 20 men from the general Lagos population were taken at heart level using mercurial sphygmomanometer during a free medical screening exercise in surlier Lagos. Similarly, the blood pressure of 20 consecutive known diabetic men was taken at heart level using a mercurial sphygmomanometer. The diabetic patients were recruited from the endocrinology clinic of the Lagos State University Teaching Hospital, Ikeja, Lagos, Nigeria. Individual consent was obtained from both groups of participants. The pulse pressure of each individual was computed by subtracting the diastolic blood pressure from the systolic blood pressure. The mean arterial pressure of each individual was

Table I Statistical analysis of mean arterial pressure (map), pulse pressure (

\begin{tabular}{|c|c|c|c|c|c|c|}
\hline & & Age & Systolic & Diastolic & PP & MAP \\
\hline \multirow[t]{2}{*}{$\mathrm{N}$} & Valid & 20 & 20 & 20 & 20 & 20 \\
\hline & Missing & 0 & 0 & 0 & 0 & 0 \\
\hline Mean & & 49.8 & 138.45 & 87.75 & 50.7 & 104.649 \\
\hline Std. Error of Mean & & 3.02411 & 8.80983 & 4.24008 & 5.13097 & 5.65721 \\
\hline Median & & 52.5 & 130 & 80 & 41 & 96.67 \\
\hline Mode & & 31 & 130 & 80 & 40 & $93.33^{\mathrm{a}}$ \\
\hline Std. Deviation & & 13.52425 & 39.39874 & 18.96222 & 22.94639 & 25.29982 \\
\hline Variance & & 182.905 & 1552.261 & 359.566 & 526.537 & 640.081 \\
\hline Skewness & & -0.143 & 2.232 & 1.372 & 2.506 & 1.814 \\
\hline Std. Error of Skewness & & 0.512 & 0.512 & 0.512 & 0.512 & 0.512 \\
\hline Range & & 39 & 170 & 80 & 100 & 110 \\
\hline Minimum & & 31 & 100 & 60 & 30 & 73.33 \\
\hline Maximum & & 70 & 270 & 140 & 130 & 183.33 \\
\hline
\end{tabular}

aultiple modes exist. The smallest value is shown

computed by adding one third of the pulse pressure to the diastolic blood pressure. The limitation of this study includes the very small size of the study population and Africans are not well represented in the sample size. The study was analysed using SPSS version 17.0 version.

\section{Statistical analysis}

By using descriptive statistics among the non-diabetics male Africans, the mean of the ages was 49.8 years with standard error of the mean of 3.02,the median was 52.5 years with mode of 31 years. The standard deviation was 13.5 with -0.143 Skewness, the least age was 31 and the highest was 70.The range of Mean Arterial Pressure was $110 \mathrm{mmHg}$, the lowest value was 73.33 while the highest was 183.33 , the mean was 104.64 while the standard error of the mean was 5.6 , the median was 96.67 , the distribution was bimodal with values of $93.3 \mathrm{mmHg}$ and $96.67 \mathrm{mmHg}$. The standard deviation was 25.29 with a variance of 640.08 ; the Skewness was 1.81 with standard error of skewness of 0.512 (Table 1). The pulse pressure range was $100 \mathrm{mmHg}$, the least value was $30 \mathrm{mmHg}$ while the maximum was $130 \mathrm{mmHg}$.the mean was $50.70 \mathrm{mmHg}$ while the standard error of the mean was 5.13, the standard deviation was 22.94 while the variance was 526.53.The Skewness was 2.50 with standard error of Skewness of 0.512 . By using Pearson correlation (Table 2), age correlated fairly well with pulse pressure with a value of 0.408 and p-value of 0.075 compared to mean arterial pressure where the correlation was 0.294 with a p-value of 0.209.Similarly,pulse pressure in these non-diabetics correlated significantly well with mean arterial pressure with a value of 0.876 with p-value of 0.0001 . By using descriptive statistics among the diabetic Africans (Table 3), the mean of the ages was 67.4 years with a standard error of the mean of 2.61, and the median was 69.5 years with a mode of 65 years. The standard deviation was 11.69 with Skewness of -1.863 , the least age was 31 years and the highest was 82.The range of the mean arterial pressure was $60 \mathrm{mmHg}$, the lowest value was $73.33 \mathrm{mmHg}$ while the highest was 133.33 , the mean was $96.96 \mathrm{mmHg}$ while the standard error of the mean was 4.06 , the median was $95 \mathrm{mmHg}$,the distribution of mean arterial pressure was bimodal with values of $80 \mathrm{mmHg}$ and $96.67 \mathrm{mmHg}$, the standard deviation was 18.17 with a variance of 330.26 , the Skewness was 0.67 with standard error of Skewness of 0.512 
Table 2 Pearson correlation of mean arterial pressure (map) and pulse pressure (pP) in non diabetic male Africans

\begin{tabular}{|c|c|c|c|c|c|c|}
\hline & & Age & Systolic & Diastolic & $\mathbf{P P}$ & MAP \\
\hline \multirow[t]{5}{*}{ AGE } & Pearson Correlation & 1 & 0.347 & 0.227 & 0.408 & 0.294 \\
\hline & Sig. (2-tailed) & & 0.134 & 0.335 & 0.075 & 0.209 \\
\hline & Sum of Squares and Cross-products & 3475.2 & 3510.8 & 1108 & 2402.8 & 1908.816 \\
\hline & Covariance & 182.905 & 184.779 & 58.316 & 126.463 & 100.464 \\
\hline & $\mathrm{N}$ & 20 & 20 & 20 & 20 & 20 \\
\hline \multirow[t]{5}{*}{ SYSTOLIC } & Pearson Correlation & 0.347 & 1 & $.927 * *$ & $.951 * *$ & $.982 * *$ \\
\hline & Sig. (2-tailed) & 0.134 & & 0 & 0 & 0 \\
\hline & Sum of Squares and Cross-products & 3510.8 & 29492.95 & 13160.25 & 16332.7 & 18603.89 \\
\hline & Covariance & 184.779 & 1552.261 & 692.645 & 859.616 & 979.152 \\
\hline & $\mathrm{N}$ & 20 & 20 & 20 & 20 & 20 \\
\hline \multirow[t]{5}{*}{ DIASTOLIC } & Pearson Correlation & 0.227 & $.927 * *$ & 1 & $.765 * *$ & $.981 * *$ \\
\hline & Sig. (2-tailed) & 0.335 & 0 & & 0 & 0 \\
\hline & Sum of Squares and Cross-products & 1108 & 13160.25 & 6831.75 & 6328.5 & 8940.955 \\
\hline & Covariance & 58.316 & 692.645 & 359.566 & 333.079 & 470.577 \\
\hline & $\mathrm{N}$ & 20 & 20 & 20 & 20 & 20 \\
\hline \multirow[t]{5}{*}{ PP } & Pearson Correlation & 0.408 & $.951 * *$ & $.765 * *$ & 1 & $.876^{* *}$ \\
\hline & Sig. (2-tailed) & 0.075 & 0 & 0 & & 0 \\
\hline & Sum of Squares and Cross-products & 2402.8 & 16332.7 & 6328.5 & 10004.2 & 9662.934 \\
\hline & Covariance & 126.463 & 859.616 & 333.079 & 526.537 & 508.575 \\
\hline & $\mathrm{N}$ & 20 & 20 & 20 & 20 & 20 \\
\hline \multirow[t]{5}{*}{ MAP } & Pearson Correlation & 0.294 & $.982 * *$ & $.981 * *$ & $.876^{* *}$ & 1 \\
\hline & Sig. (2-tailed) & 0.209 & 0 & 0 & 0 & \\
\hline & Sum of Squares and Cross-products & 1908.816 & 18603.89 & 8940.955 & 9662.934 & 12161.54 \\
\hline & Covariance & 100.464 & 979.152 & 470.577 & 508.575 & 640.081 \\
\hline & $\mathrm{N}$ & 20 & 20 & 20 & 20 & 20 \\
\hline
\end{tabular}

**Correlation is significant at the 0.0 I level (2-tailed).

Table 3 Statistical analysis of mean arterial pressure (map) and pulse pressure (pp) in diabetic male Africans

\begin{tabular}{lllllll}
\hline & Age & Systolic & Diastolic & PP & MAP & FBS \\
\hline N Valid & 20 & 20 & 20 & 20 & 20 & 20 \\
Missing & 0 & 0 & 0 & 0 & 0 & 0 \\
Mean & 67.4 & 142.1 & 74.4 & 67.7 & 96.9665 & 143.1 \\
Std. Error of Mean & 2.61514 & 5.23445 & 4.28117 & 4.66628 & 4.06366 & 13.54095 \\
Median & 69.5 & 145 & 70 & 64 & 95 & 126.5 \\
Mode & $65.00^{\mathrm{a}}$ & 120 & 70 & 60 & $80.00^{\mathrm{a}}$ & 111 \\
Std. Deviation & 11.69525 & 23.40917 & 19.14598 & 20.86826 & 18.17325 & 60.55698 \\
Variance & 136.779 & 547.989 & 366.568 & 435.484 & 330.267 & 3667.147 \\
Skewness & -1.863 & -0.11 & 0.493 & 0.383 & 0.674 & 1.203 \\
Std. Error of Skewness & 0.512 & 0.512 & 0.512 & 0.512 & 0.512 & 0.512 \\
Range & 51 & 80 & 70 & 80 & 60 & 200 \\
Minimum & 31 & 100 & 40 & 30 & 73.33 & 73 \\
Maximum & 82 & 180 & 110 & 110 & 133.33 & 273 \\
\hline
\end{tabular}

a Multiple modes exist. The smallest value is shown 
Table 4 Pearson correlation of mean arterial pressure (map) and pulse pressure (pp) in diabetic male Africans

\begin{tabular}{|c|c|c|c|c|c|c|c|}
\hline & & Age & Systolic & Diastolic & $\mathbf{P P}$ & MAP & FBS \\
\hline \multirow[t]{5}{*}{ Age } & Pearson Correlation & 1 & 0.077 & -0.164 & 0.237 & -0.082 & 0.056 \\
\hline & Sig. (2-tailed) & & 0.747 & 0.489 & 0.314 & 0.73 & 0.815 \\
\hline & Sum of Squares and Cross-products & 2598.8 & 401.2 & -699.2 & 1100.4 & -332.392 & 751.2 \\
\hline & Covariance & 136.779 & 21.116 & -36.8 & 57.916 & -17.494 & 39.537 \\
\hline & $\mathrm{N}$ & 20 & 20 & 20 & 20 & 20 & 20 \\
\hline \multirow[t]{5}{*}{ Systolic } & Pearson Correlation & 0.077 & 1 & $.534 *$ & $.631 * *$ & $.805 * *$ & 0.05 \\
\hline & Sig. (2-tailed) & 0.747 & & 0.015 & 0.003 & 0 & 0.835 \\
\hline & Sum of Squares and Cross-products & 401.2 & 10411.8 & 4551.2 & 5860.6 & 6504.747 & 1341.8 \\
\hline & Covariance & 21.116 & 547.989 & 239.537 & 308.453 & 342.355 & 70.621 \\
\hline & $\mathrm{N}$ & 20 & 20 & 20 & 20 & 20 & 20 \\
\hline \multirow[t]{5}{*}{ Diastolic } & Pearson Correlation & -0.164 & $.534 *$ & 1 & -0.318 & $.932 * *$ & 0.034 \\
\hline & Sig. (2-tailed) & 0.489 & 0.015 & & 0.172 & 0 & 0.887 \\
\hline & Sum of Squares and Cross-products & -699.2 & 4551.2 & 6964.8 & -2413.6 & 6160.248 & 749.2 \\
\hline & Covariance & -36.8 & 239.537 & 366.568 & -127.032 & 324.224 & 39.432 \\
\hline & $\mathrm{N}$ & 20 & 20 & 20 & 20 & 20 & 20 \\
\hline \multirow[t]{5}{*}{ PP } & Pearson Correlation & 0.237 & $.631 * *$ & -0.318 & 1 & 0.048 & 0.025 \\
\hline & Sig. (2-tailed) & 0.314 & 0.003 & 0.172 & & 0.841 & 0.918 \\
\hline & Sum of Squares and Cross-products & 1100.4 & 5860.6 & -2413.6 & 8274.2 & 344.499 & 592.6 \\
\hline & Covariance & 57.916 & 308.453 & -127.032 & 435.484 & 18.132 & 31.189 \\
\hline & $\mathrm{N}$ & 20 & 20 & 20 & 20 & 20 & 20 \\
\hline \multirow[t]{5}{*}{ MAP } & Pearson Correlation & -0.082 & $.805 * *$ & $.932 * *$ & 0.048 & 1 & 0.045 \\
\hline & Sig. (2-tailed) & 0.73 & 0 & 0 & 0.841 & & 0.85 \\
\hline & Sum of Squares and Cross-products & -332.392 & 6504.747 & 6160.248 & 344.499 & 6275.073 & 946.107 \\
\hline & Covariance & -17.494 & 342.355 & 324.224 & 18.132 & 330.267 & 49.795 \\
\hline & $\mathrm{N}$ & 20 & 20 & 20 & 20 & 20 & 20 \\
\hline \multirow[t]{5}{*}{ FBS } & Pearson Correlation & 0.056 & 0.05 & 0.034 & 0.025 & 0.045 & 1 \\
\hline & Sig. (2-tailed) & 0.815 & 0.835 & 0.887 & 0.918 & 0.85 & \\
\hline & Sum of Squares and Cross-products & 751.2 & 1341.8 & 749.2 & 592.6 & 946.107 & 69675.8 \\
\hline & Covariance & 39.537 & 70.621 & 39.432 & 31.189 & 49.795 & 3667.147 \\
\hline & $\mathrm{N}$ & 20 & 20 & 20 & 20 & 20 & 20 \\
\hline
\end{tabular}

*Correlation is significant at the 0.05 level (2-tailed).

**Correlation is significant at the 0.01 level (2-tailed).

The pulse pressure range was $80 \mathrm{mmHg}$, the least was $30 \mathrm{mmHg}$ and the highest was $110 \mathrm{mmHg}$, the mean was $67.7 \mathrm{mmHg}$, with a standard error of the mean of 4.6 , the median was $64 \mathrm{mmHg}$, the mode was $60 \mathrm{mmHg}$, the standard deviation was 20.86 while the variance was 435.48 .The Skewness was 0.383 with standards error of Skewness of 0.512 . The fasting blood sugar range was $200 \mathrm{mg} / \mathrm{dl}$, the least was $73 \mathrm{mg} / \mathrm{dl}$ and the highest was $273 \mathrm{mg} / \mathrm{dl}$, the mean was $143.1 \mathrm{mg} / \mathrm{dl}$ with a standard error of the mean of 13.54 , the median was $126.5 \mathrm{mg} / \mathrm{dl}$, the mode was $111 \mathrm{mg} / \mathrm{dl}$, the standard deviation was 60.55 while the variance was 3667.1.The Skewness was 1.203 with 
standard error of Skewness of 0.512. By using the person correlate among these diabetic Africans (Table 4), age was inversely correlated to mean arterial pressure with value of -0.082 with p-value 0.730 , it correlated poorly with pulse pressure with values of 0.237 and p-value 0.314 ,age correlation value to fasting blood sugar was not significant with a value of 0.056 and a p-value of 0.815 .In diabetics Africans, no significant correlation between pulse pressure with mean arterial pressure and fasting blood sugar with values of 0.048 ,p-value 0.841 and $0.025, \mathrm{p}$-value 0.918 . Similarly,Mean arterial pressure has no significant correlation with fasting blood sugar with values of $0.045, \mathrm{p}$-value 0.850 .

\section{Results}

The cohorts studied consist of 20 male non diabetic Africans and 20 known diabetic males in Nigeria Africa. The age range of the non diabetic is 31 to 70 years with a mean age of 49.8 years while the age range of the diabetics was 31 to 82 years with mean age of 67.4 years. The mean pulse pressure among the non diabetic was $46.5 \mathrm{mmHg}$ while the mean pulse pressure among the diabetics was $67.7 \mathrm{mmHg}$. Among the non diabetic the mean of the mean arterial pressure was $103.20 \mathrm{mmHg}$ while among the diabetics it was $96.97 \mathrm{mmHg}$. In both diabetic and non diabetic group, $20 \%$ of participants (4 in each group) had mean arterial pressure above $110 \mathrm{mmHg}$. The highest mean arterial pressure among the diabetic group was $133.33 \mathrm{mmHg}$ while the highest among the non diabetic was $150 \mathrm{mmHg}$. The lowest mean arterial pressure in the diabetic group was $73.33 \mathrm{mmHg}$. The lowest mean arterial pressure in the non diabetic group was the same figure.

\section{Discussion}

This paper shows that mean arterial pressure is higher in the general African male population than among diabetic male Africans, this is probably because other risk factors for higher mean arterial pressure are in the general population. Also this paper suggest that diabetes mellitus is not the worst cause of high mean arterial pressure as the highest mean arterial pressure of $150 \mathrm{mmHg}$ was in the general male population studied compared to the highest of 133.33 among the diabetic group. This supports autopsy finding in literature that hemorrhagic cerebrovascular accident occurs slightly more commonly in non diabetic compared to diabetics while cerebral infarction occurs more in diabetic subjects compared to non diabetics since hemorrhagic cerebrovascular accident tend to occur at higher mean arterial pressure (like $150 \mathrm{mmHg}$ ) while ischemic cerebrovascular accident occurs at lower mean arterial pressure. ${ }^{15}$ It was observed that the absolute value of each of the mean, the median and the mode were higher in non-diabetics compared to diabetics. One salient point noted in this study is that while pulse pressure correlated significantly with mean arterial pressure in non-diabetics with value of $0.876 \mathrm{p}$-value 0.0001 , there was a noticeable insignificant correlation between pulse pressure and mean arterial pressure in diabetics with value 0.048 , p-value 0.841 .The effects of chronic hyperglycaemia on the caliber of vessels overtime in diabetics will probably explain this. Similarly in non-diabetics, pulse pressure correlated significantly with systolic and diastolic blood pressure with values $0.951, \mathrm{p}$-value 0.0001 and 0.785 , $\mathrm{p}$-value 0.0001 whereas pulse pressure correlated significantly only with systolic blood pressure in diabetics with values 0.631 , p-value 0.003 while it was inversely correlated to diastolic pressure with values -0.318 , p-value 0.172 . Similarly it was noticed in the study that African diabetic male tend to have higher pulse pressure than the general African non diabetic male population as the absolute value of each of the mean, the median and the mode were higher in the male African diabetics.

\section{Conclusion}

Mean arterial pressure is lower in male African diabetics compared to the general African male population. Conversely, pulse pressure is higher among male African diabetics compared to the general African male population. One salient point noted in this study is that while pulse pressure correlated significantly with mean arterial pressure in non-diabetics with value of $0.876 \mathrm{p}$-value 0.0001 , there was a noticeable insignificant correlation between pulse pressure and mean arterial pressure in diabetics.

\section{Acknowledgment}

None.

\section{Conflict of interest}

None.

\section{References}

1. Dahai Yu, Zhanzheng Zhao, David Simmons. Interaction between Mean Arterial Pressure and HbA1c in Prediction of Cardiovascular Disease Hospitalisation: A Population-Based Case-Control Study. Journal of Diabetes Research. 2016;2016:7.

2. W Yang, TM Dall, P Halder et al. Economic costs of diabetes in the U.S. in 2012. Diabetes Care. 2013;36(4):1033-1046.

3. D Simmons, H Wenzel. Diabetes inpatients: a case of lose, lose, lose. Is it time to use a 'diabetes-attributable hospitalization cost' to assess the impact of diabetes? Diabetic Medicine. 2011;28(9):1123-1128.

4. S Kodama, C Horikawa, K Fujihara et al. Meta-analysis of the quantitative relation between pulse pressure and mean arterial pressure and cardiovascular risk in patients with diabetes mellitus. Am J Cardio. 2014;113(6):1058-1065.

5. A Cohen-Solal, F Beauvais, D Logeart. Heart failure and diabetes mellitus: epidemiology and management of an alarming association. Journal of Cardiac Failure. 2008;14(7):615-625.

6. GW Somes, M Pahor, RI Shorr, et al. The role of diastolic blood pressure when treating isolated systolic hypertension. Arch Intern Med. 1999;159(17):2004-2009.

7. AP Kengne, S Czernichow, R Huxley, et al. Blood pressure variables and cardiovascular risk: new findings from advance. Hypertension. 2009;54( 2):399-404.

8. CCL Wang, JEB Reusch. Diabetes and cardiovascular disease: changing the focus from glycemic control to improving long-term survival. Am J Cardiol. 2012;110(9):58B-68B.

9. Nichols GA, Hillier TA, Erbey JR, et al. Congestive heart failure in type 2 diabetes: prevalence, incidence, and risk factors. Diabetes Care. 2001;24(9):1614-1619.

10. Malmberg K, Yusuf S, Gerstein HC, et al. Impact of diabetes on long-term prognosis in patients with unstable angina and non-Q-wave myocardial infarction: results of the OASIS (Organization to Assess Strategies for Ischemic Syndromes) Registry. Circulation. 2000;102(9):1014-1019.

11. Dries DL, Sweitzer NK, Drazner MH, et al. Prognostic impact of diabetes mellitus in patients with heart failure according to the 
etiology of left ventricular systolic dysfunction. J Am Coll Cardiol. 2001;38(2):421-428.

12. Reusch JE, Wang CC. Cardiovascular disease in diabetes: where does glucose fit in? J Clin Endocrinol Metab. 2011;96(8):2367-2376.

13. D Yu, D Simmons. Relationship between HbA1c and risk of all-cause hospital admissions among people with Type 2 diabetes. Diabet Med. 2013;30(12):1407-1411.
14. Anthony M Dart. Should pulse pressure influence prescribing? Aust Prescr. 2017;40(1):26-29.

15. Alex M, Baron Ek, Goldenberg S, et al. An Autopsy Study of Cerebrovascular Accident in Diabetes Mellitus. Circulation. 1962;25:663-673. 